\title{
Analysis of Ocular Cyclotorsion in Lying Position after Peribulbar Block
}

\author{
AHMED H.S. ASSAF, M.D.; MONA MOHAMMAD EL FIKY, M.D.; \\ MOHMMAD ABD EL FATTAH QABEEL, M.D. and JACK MIKHAEL ZAKI MIKHAEL, M.Sc.
}

The Department of Ophthalmology, Faculty of Medicine, Ain Shams University

\begin{abstract}
Background: Cyclotorsions are movements of cyclotorsion of the eyes. The cyclotorsion of the human eye occurs with movement of the head and body, changing the original position of the corneal axis. A significant different range of cyclotorsion between a lie and a supine position was previously reported as varying from 2 to 7 degrees.
\end{abstract}

Aim of Study: The aim of this prospective study is to determine the amount of ocular cyclotorsion in supine position after peribulbar block, to avoid misalignment of the toric IOL which negates the desired effect of correcting astigmatism.

Patients and Methods: A prospective observational randomized cross sectional study included a total of 50 eyes of 50 patients undergoing cataract surgery under peribulbar anaesthesia in El-Durrah Specialized Eye Centre, in the period from March 2018 to September 2018.

Results: In this prospective series of 50 consecutive cases we observed that: The mean of cyclotorsion in the study after peribulbar block: Was (5.20 \pm 1.85 degrees), which was statistically significant greater than 0 degrees. Incyclotorsion appeared in 31 eyes $(62 \%)$ and the mean of rotation was 5.77 degrees. Excyclotorsion ocurred in 16 eyes (32\%) and the mean was 5.06 degrees. There were no cyclotorsion in 3 eyes. Cyclotorsion (1-5) degrees occurred in 27 eyes (48\%). Cyclotorsion more than 5 degrees occurred in 23 eyes $(46 \%)$.

Conclusion: Cyclotorsion represents another potential source of residual refractive errors that subsequently will lead to a reduced visual quality post-operatively. Therefore should be carefully taken into account in the pre-operative analyses.

Key Words: Ocular cyclotorsion - Lying position - Peribulbar block.

\section{Introduction}

CYCLOTORSIONS are movements of cyclotorsion of the eyes. The cyclotorsion of the human eye occurs with movement of the head and body, changing the original position of the corneal axis.

Correspondence to: Dr. Ahmed H.S. Assaf, The Department of Ophthalmology, Faculty of Medicine, Ain Shams University
A significant different range of cyclotorsion between a lie and a supine position was previously reported as varying from 2 to 7 degrees. The measurement of the rotation raised concern among refractive and cataract surgeons especially regarding astigmatism correction where a mistake in the position of the axis will lead to a significant impact in patients visual acuity [1]

Peribulbar block is one of the techniques for anaesthesia for cataract surgery and is one of the most popular throughout the world because it is a safe procedure and it is able to warrant a cataract surgery with no pain [2].

The objective is not only the analgesia but also ocular akinesia during the surgical procedure. It is believed that after the peribulbar block, the torsional motion of the eye suffers distortions, which could result in consequences if not evaluated prior to surgery procedure [3]

Toric Intraocular Lenses (IOLs) are spherocylinderical and correct for corneal astigamatism after cataract surgery. The orientation of the toric IOL in the capsular bag is critical because misaligment negates the desired effect of correcting astigmatism. If, for instance, a toric IOL rotates 30 degrees off the prescribed axis of alignment, there is virtually no correction of astigmatism; if it rotates more than 45 degrees from the prescribed axis, the IOL augments the pre-operative ocular cylinder [4]

\section{Patients and Methods}

A prospective observational randomized cross sectional study included a total of 50 eyes of 50 patients undergoing cataract surgery under peribulbar anaesthesia in El-Durrah Specialized Eye Centre, in the period from March 2018 to September 2018. 


\section{Inclusion criteria:}

1- Patient with immature cataract.

2- Axial length within $22 \mathrm{~mm}$ to $26 \mathrm{~mm}$.

\section{Exclusion criteria:}

1- Patients with very shallow or very deep orbit.

2- Strabismus.

3- Any organic eye disease.

4- History of ocular trauma.

5- History of intraocular or refractive surgery.

Assessment of selected patients:

- All patients were subjected to:

1- Medical history taking.

2- Visual acuity assessment using auto refractometer, refraction and best corrected visual acuity assessment using Snellen chart.

3- Slit lamp examination of anterior segment.

4- Fundus examination through dilated pupil using slit lamp bimicroscopy with +90 diopters lens.

5- Prism and cover test.

6- Assessment of ocular motility and extraocular muscles.

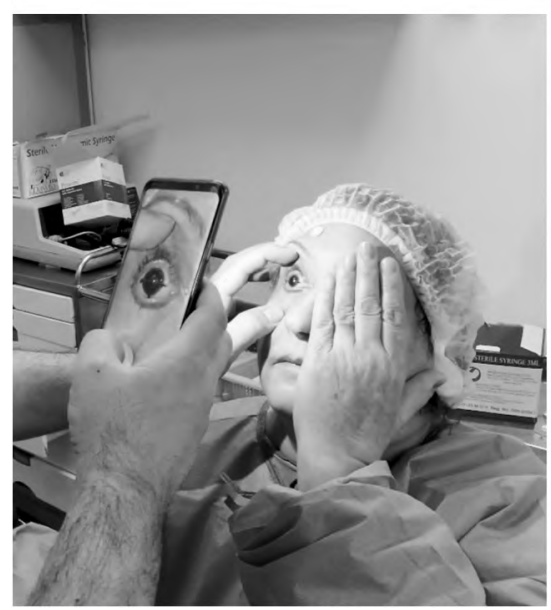

7- Ocular Biometery using IOL master to calculate the axial length.

8- Freehand perilimbal marking: A surgical marking pen was used to mark the limbus at 3-, 6and 9-o'clock Fig. (1).

9- iToric Patwardhan smartphone application: The iToric is a newly developed smartphone application. Its main aim is to improve the accuracy of pre-operative reference markings prior to toric IOL implanation. It further provides a photographic analysis to identify the rotational deviation of the marks from the real horizontal meridian. The iToric application can be downloaded from the App Store for free. In this study, the iToric application was used in every eye immediately after freehand marking method Fig. (2).

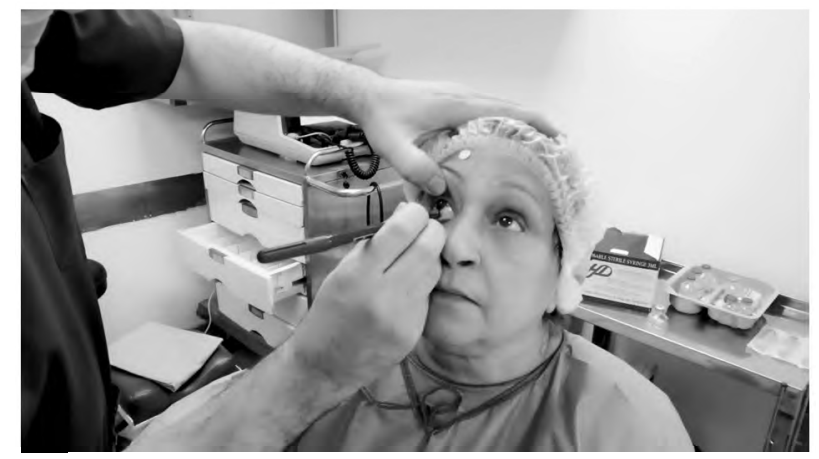

Fig. (1): Freehand perilimbal marking.

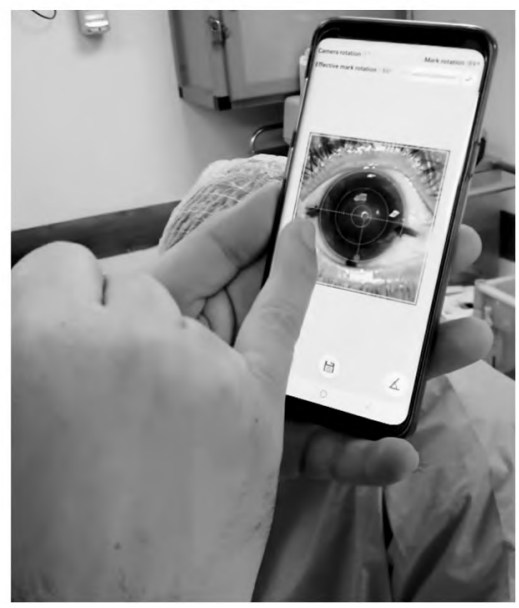

Fig. (2): Using iToric Patwardhan smartphone app.

10- Peribulbar anaesthesia: All cases were done under single injection-medial site technique of peribulbar block using a mixture of bupivacain $(0.75 \%, 6 \mathrm{ml})$ lidocaine $(1.0 \%, 3 \mathrm{ml})$ and hyaluronidase $(1 \mathrm{ml})$. Using a $24-\mathrm{mm}, 23$ to 26 gauge needle, by single anaethesiologist. After negative aspiration, volume of $5 \mathrm{ml}$ of local anaethetic solution was slowly injected followed by 10 minutes of intermittent ocular compression, ocular movements were assessed at 5 and $10 \mathrm{~min}$ after the block.
11- Using surgical microscope while the patient was on the surgical table in supine position and head position was aligned, the horizontal axis $(0$ and 180, 3 and 9 o'clock) was marked again on the corneal limbus using a marking pen Fig. (3).

Ocular cyclotorsion and its direction, which was the difference between two horizontal lines,was measured using a Mendez degree gauage Fig. (4). 


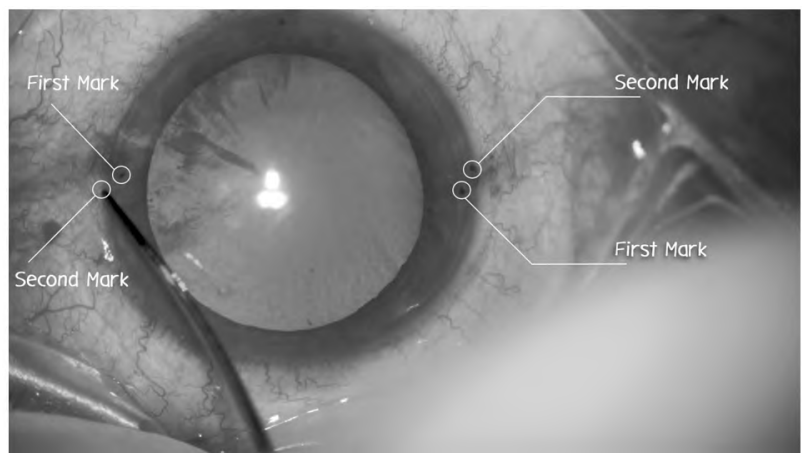

Fig. (3): Initiation of new marks.

\section{Statistical analysis:}

Data were collected, revised, coded and entered to the Statistical Package for Social Science (IBM SPSS) version 23 . The quantitative data were presented as mean, standard deviations and ranges when parametric. Also qualitative variables were

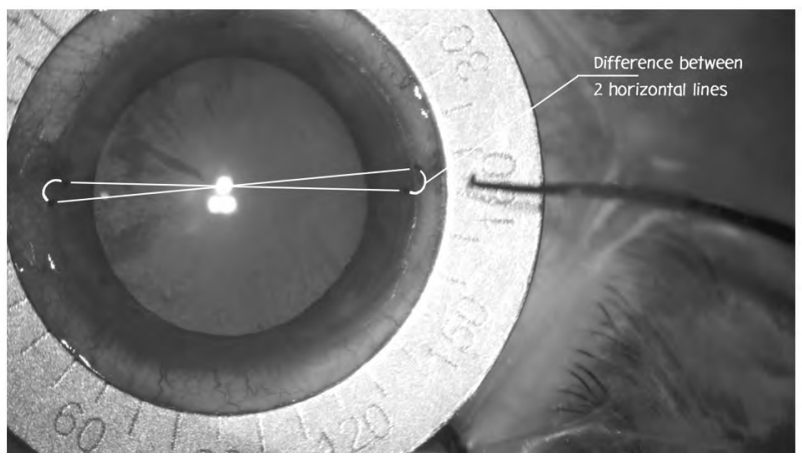

Fig. (4): Measuring the degree of cyclotorsion.

presented as number and percentages. So, the $p$ value was considered significant as the following: $p$-value $>0.05$ : Non significant (NS), $p$-value $<0.05$ : Significant (S), $p$-value <0.01: Highly significant (HS).

\section{Results}

Table (1): Demographic data of the study group.

\begin{tabular}{|c|c|c|c|c|c|c|}
\hline & $\begin{array}{c}\text { No cyclotorsion } \\
\text { No. }=3\end{array}$ & $\begin{array}{l}\text { Incyclotorsion } \\
\text { No. }=31\end{array}$ & $\begin{array}{l}\text { Exyclotorsion } \\
\text { No. }=16\end{array}$ & $\begin{array}{c}\text { Test } \\
\text { value }\end{array}$ & $\begin{array}{c}p- \\
\text { value }\end{array}$ & Sig. \\
\hline \multicolumn{7}{|l|}{ Age: } \\
\hline Mean \pm SD & $67.00 \pm 2.65$ & $62.77 \pm 6.70$ & $63.56 \pm 5.80$ & $0.640 \bullet$ & 0.532 & NS \\
\hline Range & $65-70$ & $53-75$ & $53-71$ & & & \\
\hline \multicolumn{7}{|l|}{ Gender: } \\
\hline Female & $1(33.3 \%)$ & $22(71.0 \%)$ & $8(50.0 \%)$ & $3.082^{*}$ & 0.214 & NS \\
\hline Male & $2(66.7 \%)$ & $9 \quad(29.0 \%)$ & $8(50.0 \%)$ & & & \\
\hline \multicolumn{7}{|l|}{ Eye: } \\
\hline OD & $1(33.3 \%)$ & $17(54.8 \%)$ & $5 \quad(31.3 \%)$ & $2.570^{*}$ & 0.277 & NS \\
\hline OS & $2(66.7 \%)$ & $14(45.2 \%)$ & $11(68.8 \%)$ & & & \\
\hline
\end{tabular}

Fifty eyes of fifty patients undergoing cataract surgery under peribulbar anaesthesia were selected for this prospective observational randomized study (Table 1).

Table (2) shows that 50 eyes with peribulbar block, the deviation was Incyclotorsion with 31 eyes $(62 \%)$, excyclotorsion with 16 eyes $(32 \%)$ and 3 eyes were without deviation (6\%).

Table (3) shows the measured cyclotorsional deviation after peribulbar block which were located around 5.77 degrees of incyclotorsion and 5.06 degrees of excyclotorsion movement and a mean of cyclotorsion of 5.20 degrees.

Table (2): Percentage of Cyclotorsion movement among study group.

\begin{tabular}{lll}
\hline Movement & No. & $\%$ \\
\hline Incyclotorsion & 31 & 62 \\
Excyclotorsion & 16 & 32 \\
No cyclotorsion & 3 & 6.0 \\
\hline
\end{tabular}


Table (3): Comparison between no cyclotorsion, incyclotorsion and exyclotorsion regarding degree of cyclotorsion.

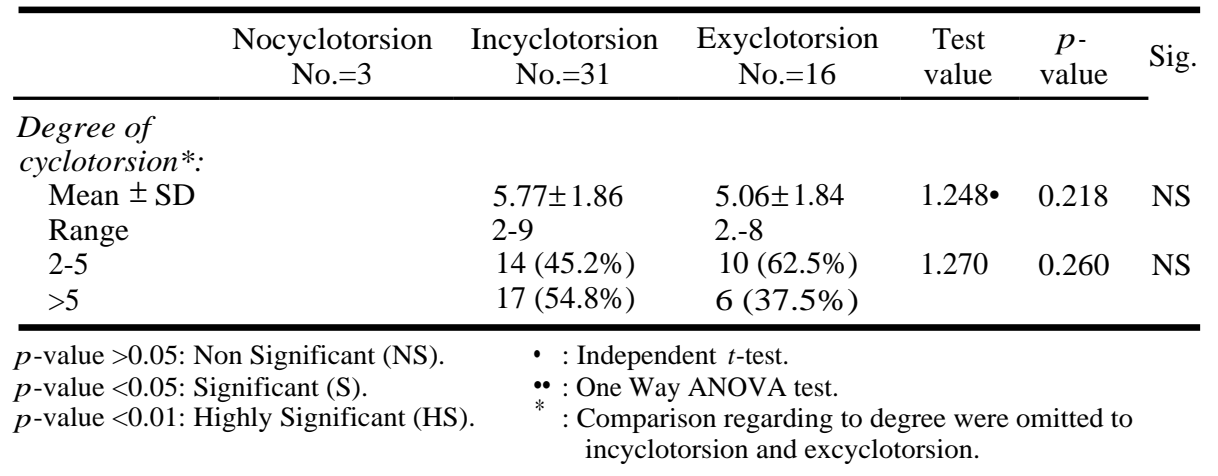

\section{Discussion}

This prospective study included 50 consecutive cases, their age ranging from 53 to 75 years old with balanced study group according to gender (males 38\%, females 62\%) and laterality (OD 46\%, OS 54\%), with no significant relationship between results and demographic data.

In this study, there were 47 eyes $(94 \%)$ which had cyclotorsion movement after peribulbar anaesthesia versus 3 eyes $(6 \%)$ which had no cyclotorsion movement. Kara-Junior et al., [5] recored that all cases $(100 \%)$ had cyclotorsion after peribulbar anaesthesia. Despite the apparent akinesia achieved with peribulbar block, cyclotorsion persists.

We also evaluated the degree of cyclotorsion, it was located around 5.77 degrees of incyclotorsion (62\%), and 5.06 degrees of excyclotorsion (32\%), with mean of cyclotorsion located around 5.20 degrees. These results are consistant with the previously mentioned study done by Kara-Junior et al., [5] they recorded deviation located around 5.68 degrees of incyclotorsion (61\%) and 4.81 degrees of excyclotorsion (39\%) and a mean of cyclotorsion located around 4.92 degrees.

In another comparison with other studies which evaluated cyclotorsion without peribulbar anaesthesia as Kim and Joo, [1] the mean of cyclotorsion was 2.59. Chang, [3] the mean of cyclotorsion was 2.67. Swami et al., [6] recorded the highest mean of cyclotorsion that was 4.1 degrees. According to the above mentioned data, it is concluded that the degree of cyclotorsion with peribulbar anaesthesia is rather higher than that related to body position without peribulbar anaesthesia.

We also observed that cyclotorsion ranging (2$5)$ degrees occurred in 24 eyes (48\%) and cyclotorsion more than 5 degrees occurred in 23 eyes $(46 \%)$. Our result is different from study done by
Febbraro et al., [7] without peribulbar anaesthesia recording lower incidence of cyclotorsion greater than 5 degrees with (29\%), and also the study done by Kim and Joo, [1] without peribulbar anaesthesia recording least incidence of cyclotorsion greater than 5 degrees with (13\%).

Our greater incidence of cyclotorsion more than 5 degrees in contrast of these studies, can be explained by the fact that both of them didn't use peribulbar anaesthesia. So we concluded that there is an increase in cyclotorsion degree with peribulbar anaesthesia. So, induced inexcyclotorsion is an important factor in the outcome of cataract surgery especially with peribulbar anaesthesia or even topical anaesthesia.

We also tried from our study to find an answer for this question, "Is there specific movement (direction/amount) of the eye post peribulbar anaesthesia, which help us to detect the horizontal meridian (0-180 degree), while patient is on surgical table after peribulbar anaesthesia, without depending on perilimbal marks before anaesthesia??" Our study showed that this movemet is variable in direction and amount.

Although cyclotorsion of the eye has no impact in case of monofocal IOL implanation, it is a possible cause of axial misalignment and residual astigmatism in case of toric IOL implantation.

The current method used to compensate for ocular cyclotorsion is to mark a horizontal reference line at the 0 -and 180-degree positions of the limbus. According to the horizontal reference line, we determined the axis of the toric IOL intraoperatively, with the patient in the supine position.

It is known that a rotation of 6 degrees can reduce the effect of an astigmatic correction by approximately $20 \%$ [11], a 10-degree axis shift decreases the efficiency of the desired cylinder 
correction by more than $30 \%$. Even minimal meridional errors can have significant negative refractive consequences, particularly in cases of moderate to high astigmatism [7].

In case of misalignment of the toric IOL with postoperative refractive surprise, the spherical equivalent of the manifest refraction is zero like -1DSph/+2Dcyl @80 degrees. Its advisable to take up the patient early within 1 to 3 weeks for reliagnment to prevent adhesions forming between the lens and the capsular bag. Sites such as astigmatismfix.com have formula designed by John Berdahl and David Hardten, which give you the amount of rotation which needs to be performed based on the manifest refraction of the patient [8].

Intraocular lens rotation should be the preferred choice if: (1) The surgeon expects the corrective rotation will reduce the manifest refractive cylinder to an acceptable level. (2) The surgeon knows how much and in which direction to rotate the IOL. (3) The surgeon is capable of performing the desired rotation. The challenges in rotating a toric IOL to reduce manifest refractive cylinder have been considered [9].

\section{Conclusion:}

Cyclotorsion represents another potential source of residual refractive errors that subsequently will lead to a reduced visual quality post-operatively. Therefore should be carefully taken into account in the pre-operative analyses.

As a consequence, it has been recommended that pre-operative corneal markings of the 0-to 180-degree meridian using specifically designed instruments should be made with the patient upright and that the markings should then be aligned with the 0-to 180-degree meridian of a fixation ring with the patient supine, from which the meridian of the toric IOL to be implanted could be marked with a meridian marker.

\section{References}

1- KIM H. and JOO C.K.: Ocular cyclotorsion according to body position and flap creation before laser in situ keratomileusis. J. Cataract. Refract. Surg., 34 (4): 55761, 2008.

2- CLAUSEL H., TOUFFET L., HAVAUX M., LAMARD M., SAVEAN J., COCHENER B., et al.: Peribulbar anathesia: Efficacy of a single injection with a limited local anasthetic volume). J. Fr. Ophthalmol., 31 (8): 7815, 2008.

3- CHANG J.: Cyclotorsion during laser in situ keratomileusis. J. Cataract. Refract. Surg., 34 (10): 1720-6, 2008.

4- NOVIS C.: Astigmatism and toric intraocular lenses. Curr. Opin. Ophthalmol., 11 (1): 47-50, 2000.

5- KARA-JUNIOR N., MOURAD P.C., MORAES R.L., et al.: Analysis of ocular cyclotorsion in lying position after peribulbar block and topical anathesia. Rev. Bras. Opthalmol., 73 (4): 199-201, 2014.

6- SWAMI A.U., STEINERT R.F., OSBORNE W.E. and WHITE A.A.: Rotational malposition during laser in situ keratomileusis. AM. J. Ophthalmol., 133 (4): 561-2, 2002.

7- FEBBRARO J.L., KOCH D.D., KHAN H.N., SAAD A. and GATINEL D.: Detection of static cyclotorsion in laser in situ keratomileusis. J. Cataract. Refract. Surg., 36 (10): 1718-23, 2010.

8- VIJAYA LAKSHMI B. and IRFAN FARAZ: Tackling refractive surprise post cataract surgery-A surgeon's nightmare. MedPulse International Journal of Ophthalmology. September, 3 (3): 79-83, 2017.

9- ALPINS N., ONG J.K. and STAMATELATOS G.: Refreactive surprise after toric intraocular lens implantation: Graph analysis. J. Cataract. Refract. Surg., Feb., 40 (2): 283-94, 2014.

10- FAROOQUI J.H., KOUL A., DUTTA R. and SHROFF N.M.: Comparison of two different methods of preoperative marking for toric intraocular lens implantation: Bubble marker versus pendulum marker. Int. J. Ophthalmol., 9: 703-6, 2016

11-BAYRAMLAR H., DAG Y., KARADAG R. and CAKICI O.: An easy and practical method for toric intraocular lens implantation: Marking corneal astigmatic axis at slitlamp. Int. Ophthalmol. Epub., 37 (1): 179-84, 2016.

12- HUNG-YUAN L., YI-TING F., YA-JUNG C., JUSTIN N.K., HSIN-YANG C., SZU-YUAN L., PI-JUNG L. and MING C.: A comparison of three different corneal marking methods used to determine cyclotorsion in the horizontal meridian, 11: 311-5, 2017.

13- IGARASHI A., KAMIYA K. and SHIMIZU K.: Clinical evaluation of accuracy of horizontal meridian limbal marking. Optom. Vis. Sci., 90: 540-5, 2013.

14- KHATIB Z., HALDIPURKAR S., SHETTY V. and SETIA M.: Verion vs manual marking and smartphone-assisted manual marking in toric IOL implantation. September 23, 2018. Vienna 2018 36th Congress of ESCRS. Laxmi Eye Institute, Navi Mumbai. [pending publication].

15- LEONARD C.: Smartphone Apps for cataract Surgery. Review of Ophthalmology, Published 5 September, 2019.

16- PALLAS A., TUN K.Y., MICHELLE T. and GRAHAM B.: Evaluation of the accuracy of two marking methods and the novel toriCAM application for toric intraocular lens alignment. Journal of Refractive Surgery, 34 (3): 150-5, 2018. 


\section{تحليل درجة إلتفاف العين فى الوضع راقدا بعد إعطاء التخدير المحيط بمقلة التماف العين العين}

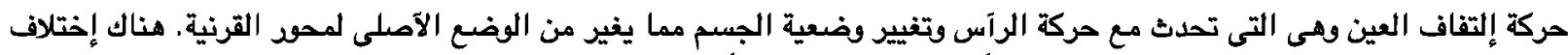

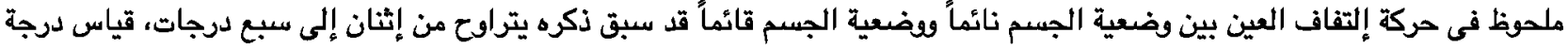

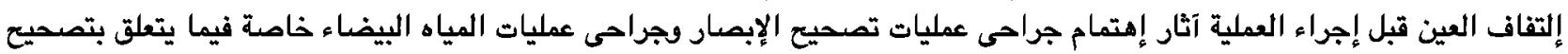

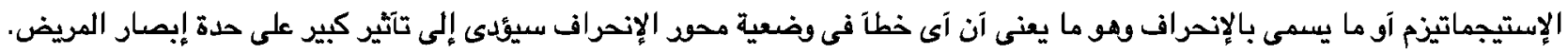

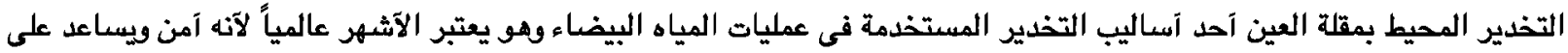

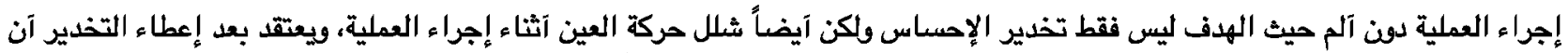

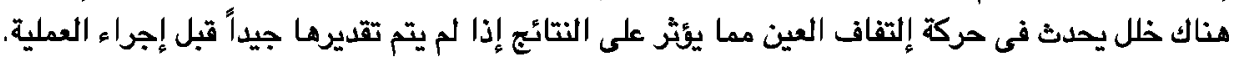

عدسات التوديك التى تزدع داخل العين هى عدسات كرية إسطوانية والتى تصح إستيجماتيزم القرنية بعد عمليات المياه البيضاء، إتجاه

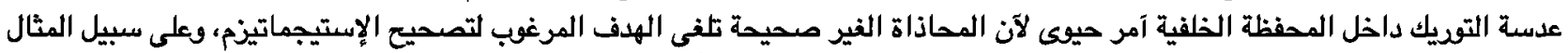

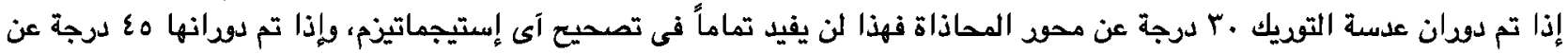

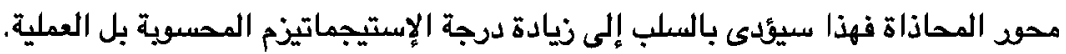

قد قمنا بلراسة مستقبلية على مرضى المياه البيضاء الذين سيخضعقن لإجراء عملية إزالة مياه بيضاء تحت ثتآثير التخدير المحيط بمقلة

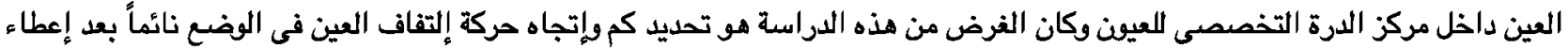

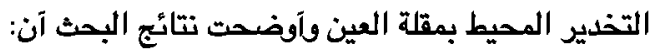

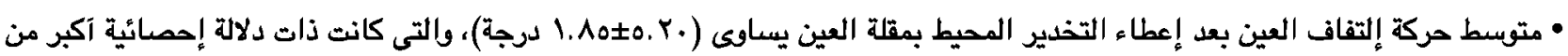
. درجة.

• ظهرت حركة إلتفاف العين إلى الداخل فى آM عيناً (T/\%) وكان متوبسط هذه الصركة O.VV درجة.

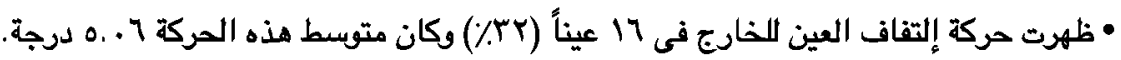
• لم تحدث حركة إلتفاف العين فى عدد ثلاثة عيون (1\%).

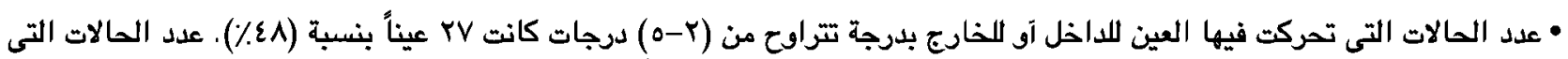

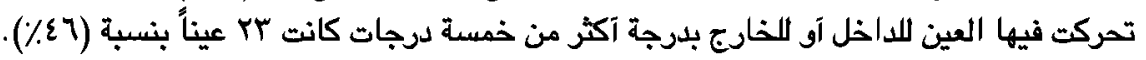

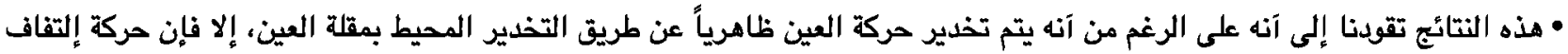
العين لا تزال موجودة.

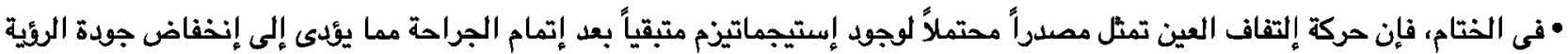

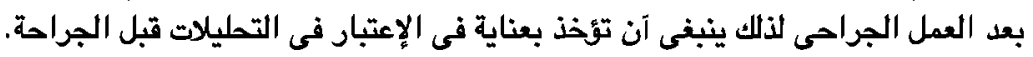

